\title{
Teachers’ Role in School-Based Assessment as Part of Public Examinations
}

\author{
Corey Williamson \\ University of West Indies (UWI), Mona, Jamaica
}

\begin{abstract}
The purpose of this paper is to first understand the concept of school-based assessment (SBA) as part of public examinations. The paper explores and discusses mainly the issues and concerns that are related to teachers' role in the use of SBA in public examinations. As to what presently is the case in the Caribbean region, SBAs are conducted based on the requirement of the different subject areas. SBA may be treated as a continuous process, seeing to the assessment of a one or more selected tasks over a significant part of the two years of work associated with a Caribbean Secondary Education Certificate (CSEC) subject or the year of study associated with a Caribbean Advanced Proficiency Examination (CAPE) unit. While the most critical implementer of SBA would be the teachers, there have been many debates about teachers' role in the implementation and the assignment of SBA scores to students in public examinations. There are concerns that the SBA implementation procedures may not be perfectly in line with public examinations model across the world. There is also the issue of fairness in the SBA processes. SBA scores generated for students are often come into questions and in most instances, the root of the concerns are with the role of the teachers involved in the SBA process.
\end{abstract}

Keywords: school-based assessment (SBA), public examination, Caribbean Examination Council (CXC)

\section{Introduction}

In the Caribbean and many other parts of the world, school-based assessment (SBA) component has become an issue of great concern in public examinations. There is presently a growing tendency for the expansion of the SBA component as it exists in many public examinations and there are many other public examination bodies across the world that are introducing the SBA component as part of their assessment process. SBA is policy-supported practice in an increasing number of educational systems around the world, including those of Australia, New Zealand, Canada, and the United Kingdom. It is increasingly being adopted as National Educational Policy in Asia as well as in some developing countries, including Ghana and Zambia. It is also actively promoted in the USA, although always over-shadowed by national testing programs.

SBA has also become a core component of the Hong Kong Certificate of Education Examination (HKCEE) in English language in 2005-2007 and was then revised and extended for the Hong Kong Diploma of Secondary Education (HKDSE).

As the expansion and introduction of SBA in public examination continues, so do the concerns and debates about this component of public examinations. The expressions of concerns about SBA in public examinations are certainly not confined to teachers. Students, parents, and school administrators also express

Corey Williamson, Ph.D. student, senior mathematics school teacher, School of Education, University of West Indies (UWI). 
concerns about the demand, fairness, and value of SBA. One recent concern about SBA is that of the teachers' role in the summative assessment of SBA as part of a public examination. This paper seeks to explore the issues relating to this concern.

\section{What is Assessment?}

The word "assess" comes from the Latin verb "assidere" meaning "to sit with." In assessment, one is supposed to sit with the learner. This implies it is something we do "with" and "for" students, but not "to" students (Green, 1998).

Griffith (2003) pointed out that assessment is a broad term that encompasses the entire process of collecting, synthesizing, and interpreting information, whether formal or informal, numerical or textual. Assessment in education may be defined as a process of collecting information about an individual or groups of individual for the purpose of making a particular educational decision.

\section{Formative and Summative Assessment}

Formative assessment refers to frequent and interactive assessments of student progress and understanding to identify learning needs and adjust teaching appropriately. Teachers using formative assessment approaches and techniques are better prepared to meet diverse students' needs through differentiation and adaptation of teaching to raise levels of student achievement and to achieve a greater equity of student outcomes (Organization for Economic Co-operation and Development [OECD], 2008). Black and William (1998) expressed that formative assessment often means no more than that the assessment is carried out frequently and is planned at the same time at which teaching is done. According to Harlen (1998), formative assessment provided feedback that led to students recognizing the (learning) gap and closing it and it is forward looking. Formative assessment includes both feedback and self-monitoring (Sadler, 1989). Tunstall and Gipps (1996) pointed out that formative assessment was used essentially to feed back into the teaching and learning process. Summative assessments are used to measure what students have learnt at the end of a unit, to promote students, to ensure they have met required standards on the way to earning certification for school completion, to enter certain occupations, or as a method for selecting students for entry into further education. Ministries or departments of education may use summative assessments and evaluations as a way to hold publicly funded schools accountable for providing quality education. Black and Wiliam (1998) made the point that summative assessment had increasingly been used to sum up learning. Summative assessment looks at past achievements, adds procedures or tests to existing work, and involves only marking and feedback grades to student. It is separated from teaching and is carried out at intervals when achievement has to be summarized and reported (Harlen, 1998).

\section{The Concept of SBA}

Broomes (1997) described SBA as a process where students as candidates undertake specified assignments during the course of the school year, under the guidance of the teacher. SBA brings assessment and teacher together for the benefits of the students and provides the teacher with the opportunity to participate in a unique way in the assessment process that leads to the final grade obtained by his/her students. 


\section{SBA in Public Examination}

In most public examination (typically formal, summative, and controlled by an agent external to the school where the student has studied) (World Bank Group, 2002a; 2002b), SBA invariably takes on the characteristics of continuous assessment. Continuous assessment refers to an assessment process that is undertaken over time and may involve a single task or a number of discrete or related tasks. In the Caribbean region, internal assessment is usually described as SBA. Its main activity includes teachers' assessment of specified assignments set according to guidelines provided by Caribbean Examination Council (CXC). Although the format of assignments may differ for some subjects, there are a number of common requirements, which include the follows:

1. Candidates must undertake specified assignments over a given period of time, fulfilling specific skills as outlined by the syllabus;

2. Class teachers must assess the work and submit the marks to CXC;

3. CXC moderates the marks awarded by the teachers;

4. Candidates' final grades should include the marks awarded as a result of this process.

In the context of CXC, the formative dimension of the SBA involves the guidance of the teacher over time and may involve a single task or a number of discrete or related tasks. The summative dimension involves the teacher assigning a final grade to students' work to be submitted as part of the students overall grade of the examination.

\section{How SBA is Used in CXC}

As outlined by Broomes (1997), SBA is used in CXC as follows:

1. Students as candidates undertake specified assignments during the course of the school year under the guidance of the teacher;

2. The teacher monitors the candidate's performance of the assignment, which may result as a process or a product;

3. The teacher assesses the candidate's work using CXC agreed criteria and report to CXC the marks awarded. This speaks to the summative dimension of the SBA component;

4. The CXC moderates the assessment done by the teacher and awards a moderated mark to the candidate. The candidate's final grade in the examination includes the moderated mark and the marks obtained for performance on the other sections of the examination.

\section{Issues Surrounding the Teacher's Role in SBA}

There is absolutely no doubt that there is cause for concerns relating to the SBA component of public examinations and especially as it relates to the involvement of the teachers in the process. There is a concern that giving the teacher a role in the summative assessment of SBA as part of a public examination weakens the value of the public examination. According to Griffith (2003), SBA has both a formative and a summative dimension. It therefore may not fit the typical public examinations model and this is often the source of anxiety among the CXC stakeholders. It is also true that SBA utilizes the scores awarded by the teacher and these contribute to the final scores or grade of students, while public examinations are typically administered by an agent external to the school where the student has studied (Griffith, 2003). 
Another issue relating to the SBA component and the involvement of the teacher is that differences in the nature and magnitude of teacher inputs into the SBA work of students may unfairly over-compensate some students while unfairly penalizing others. This is certainly a reason for the concern of giving the teacher a role in the summative assessment of the SBA in a public examination. On April 3, 2009, in an article titled “Abusing SBA projects,” Maxwell (2009) expressed concerns about the level of confidence that can be placed in the assessment of students where there was an SBA component that was open to what he saw as abuses.

According to the group, school-based marks tend to be inflated due to the assessment process, parental pressure, and in some cases, threats (p. 9). The inflation of scores due to any such reasons would interfere with public confidence (Griffith, 2003). Importantly too, the issue of fairness is in the SBA process is cannot be overlooked. The fairness in the award of scores or grades would be in question and that would be contrary to one of the important requirements of a public examination. It should be conducted in a manner that ensures that no particular candidate or group of candidates has on unfair advantage over others. All these concerns about SBA and the role of the teacher in its process tend to bring the SBA component of a public examination into question and there is even a deeper concern that the role of the teacher in the summative assessment of the SBA weakens the public examination.

\section{Understanding and Confronting the Issues}

One would want to first establish the idea that the CXC and other examination boards that include the SBA component are summative, fair, valid, and reliable. They are efficient and acceptable in and beyond their boundaries or regions. The CXC, for example, has all the characteristics and has met all the standards of a public examination. The debate continues over whether SBA should be included in public examinations and the role that teachers play in the process remains a major concern. However, it must be noted that despite of the many concerns about the SBA component in a public examination, support for teacher's involvement in the assessment of their students is widespread, particularly because of the value of this involvement in improving instruction, and ultimately, students learning (Lewis, 1997; Paris, Lawton, Turner, \& Roth, 1991; Shepard, 1995).

According to the CXC SBA Manual (CXC, 2012), validity of CXC examinations required that the teacher should be involved in assessment. Since both the formative and the summative dimensions of the SBA component, are for the most part, inter-connected, it must be clear that the teacher involvement in both dimensions of the SBA component validates the examination. SBA provides opportunities for the teacher as assessor to assess skills which cannot be adequately assessed externally by means of written tests, and as a result, it could not be that the teacher's role in the summative dimension of the SBA process weakens the examination.

\section{The Teachers' Role is Central in SBA}

It is important to note that the teachers' role is central in assessing the students' achievement for a number of reasons as follow:

1. Tests prepared by the teacher responsible for a subject provide the most appropriate measure of the students' achievement of the objective of a unit of work or of a period of instruction (CXC, 2012);

2. The relevance of teacher assessment is high since the teacher is the best judge of what has been done with the student. It stands to reason then that the role of the teacher in both the formative and the summative assessment of the SBA would make the public examination more reliable instead of weakening its value; 
3. Teacher assessment allows observation to be made on a wide sample of student behaviour, in a more natural setting than would occur in a single externally assessed paper (CXC, 2012);

4. In subjects with high practical elements, the teacher is in the best position to observe not only the students manipulative skills, but also their general work habits (CXC, 2012);

5. Teaching and testing go hand in hand. Teachers measure the effectiveness of their instruction on the assessment of the students' grasp of the objectives of the instruction. Feedback from testing allows teachers to refine their objectives, rethink their teaching strategies, select the most appropriate instructional materials and plan their next unit of work (CXC, 2012);

6. Tasks selected by teachers provide the opportunity for self-directed learning in which the student can assume responsibility for work on aspects of the subject area.

\section{SBA in Other Countries}

Apart from the CXC, the teachers' role in both the formative and the summative assessment process of SBA in other countries is also seen to be central. Darling-Hammond and McCloskey (2008) explained that SBA was a policy-supported practice that had increased in a number of educational systems around the world, including those of Australia, Bangladesh, New Zealand, Canada, the United Kingdom, Finland, Africa, Bangladesh, Northern Ireland, Hong Kong, etc.. In Bangladesh, for example, teachers have the freedom to choose the topic from the syllabus and design the class test, class work, practical work, assignment, homework, or oral presentation. It is also the teacher who is responsible to assign the final grades to students' work (Purvin, 2011).

\section{Training of Teachers}

The role of the teacher in the summative assessment of the SBA should not be seen to make the public examination weak. The CXC is among those examining boards that are cognizant of the need for training teachers to fully understand and conduct SBA. The council conducts workshops periodically for training of teachers, not only in setting SBA assignments, but also in the assessment of such assignment in keeping with the standards of the examination board.

\section{Guidance for the Conduct of SBA}

In addition to the training of teachers, CXC provides extensive guidance in its syllabuses for the conduct of SBA. The guidance includes information about what is expected in the SBA component of the examination. The provision of mark schemes or scoring rubrics for awarding marks for students' assignments is an important part of the guidance provided by the CXC. By using these schemes for the assessment, the subjectivity that may be involved becomes more objective and score-reliability is increased (Moskal, 2002).

\section{Moderation}

One of the strongest points that is often used to suppress the suggestion that the role of the teacher in the summative assessment of the SBA is the use of moderation in the SBA process. The issues of fairness to which reference is often made are, essentially, issues of teacher inconsistency and bias. Moderation procedures that are instituted by public examination boards effectively resolve these issues (Griffith, 2003). According to Broomes (1997), moderation might be described as a process of aligning the standards of different examinations or different components of an examination, conducted in different places at different times and marked by different examiners. Moderation often involves procedures prior to, during and after assessment of 
students. These procedures are designed to align the standards of different teachers in different classes, in different schools, and in different countries, to the standards of the public examination board. The CXC moderates the SBA in order to ensure that the assessment of the work of different schools carried out by different teachers using sometimes different tasks is aligned to the standard of assessment defined by CXC (2012). The concern of the moderation exercise is with the work submitted. Once, the marks awarded by the teacher for the assignment are in keeping with the CXC standards, no adjustment would be required and the council is not likely, without cause, to investigate the classroom practice that lead to the quality of an assignment in the sample moderated. This type of moderation is not confined to the CXC, but to others examination boards, such as of Australia, Bangladesh, New Zealand, Finland, Africa, and Hong Kong. Countries, such as Australia and Hong Kong, also carry out moderation in their examination process. In 1972, Queensland abolished external examinations and replaced them with a system of moderated internal assessments, and in 2008, the Hong Kong Examination and Assessment Authority (HKEAA) used statistical method to moderate SBA marks with reference to students' examination scores in order to iron out possible differences among schools in marking standards. It is the author's position that the role of the teacher in the summative assessment of the SBA is justified and should therefore not weaken the value of the examination.

\section{Conclusion}

The CXC is among those public examination boards that recognize and promote the dual role of SBA for learning and assessment of learning, encompassing, therefore, both formative and summative assessment. The CXC SBA manual for principals highlights the importance of both forms of assessment (CXC, 2012). Not only does it advise that teachers assess the work and submit the marks, it also advises that teachers make use of formative assessment procedures which can be of much benefit to both the teacher and the students. Despite the many concerns relating to SBA in the public examination, SBA plays a critical role as a component of the examination and the role of the teacher in the SBA process is central in both the formative and summative dimensions. As to the role of the teacher in the summative assessment of the SBA component of the examination, the training of teachers, the guidance provided by the examination board regarding the awarding of marks and the moderation of the final marks reported by the teacher, one can safely say that the examination is valid and reliable, and the role of the teacher in the summative assessment of the SBA process does not make the examination weak.

\section{References}

Black, P. J., \& Wiliam, D. (1998). Assessment and classroom learning. Assessment in Education: Principles, Policy, and Practice, 5(1), 7-74.

Broomes, D. (1997). Practices, problems, and potential of school-based assessment (SBA). St. Michael, Barbados: Caribbean Examinations Council (CXC)

Caribbean Examinations Council (CXC). (2012). School-based assessment (SBA) manual for principals. St. Michael, Barbados: Author.

Darling-Hammond, L., \& McCloskey, L. (2008). Assessment for learning around the world: What would it mean to be internationally competitive? Phi Delta Kappan, 90(4), 263-272.

Gipps, C., McCallum, B., \& Hargreaves, E. (2000). What makes a good primary school teacher? London: Routledge Falmer.

Green, J. M. (1998). Constructing the way forward for all students. In Innovations for Effective Schools OECD/New Zealand Joint Follow-Up Conference. New Zealand, Christchurch.

Griffith, S. (2003). School-based assessment (SBA) in public examination: A paradox that reconciles. In Opening Session of the CXC/UWI Conference on Evaluation in Education. Barbados, Divi Southwinds. 
Harlen, W. (1998). Classroom assessment: A dimension of purposes and procedures. In K. Carr (Ed.), SAME papers (pp. 75-87). Hamilton, New Zealand: Centre for Science, Mathematics, and Technology Educational Research.

Maxwell, P. (2009). Abusing school-based assessment projects. Jamaica: The Gleaner Company.

Moskal, B. (2002). Scoring rubrics: What, when and how. In L. M. Rudner, \& W. D. Schafer (Eds.), What teachers need to know about assessment (pp. 70-76). Washington, D.C.: National Education Association.

Organization for Economic Co-operation and Development (OECD). (2008). Assessment for learning: Formative assessment. Retrieved July 26, 2008, from http://www.oecd.org/site/educeri21st/40600533.pdf

Paris, S., Lawton, T. A., Turner, J. C., \& Roth, J. L. (1991). A developmental perspective on standardized achievement testing. Educational Researcher, 20, 12-20.

Purvin, N. (2011). How do secondary students in Bangladesh make sense of school-based assessment? (A Master thesis, University of Canterbury).

Sadler, R. (1989). Formative assessment and the design of instructional systems. Instructional Science, 18, 119-144.

Shepard, L. A. (1995). Using assessment to improve learning. Educational Leadership, 52, 38-43.

Tunstall, P., \& Gipps, C. (1996). Teacher feedback to young children: A typology. British Educational Research Journal, 2(4), 389-404.

World Bank Group. (2002a). Public examinations system: The nature of public examinations. Retrieved from http://www1.worldbank.org/education/exams/Nature

World Bank Group. (2002b). Public examinations system: The nature of public examinations. Retrieved from http://www1.worldbank.org/education/exams/Equity 